\title{
Targeting Tumors with Salmonella Typhimurium - Potential for Therapy
}

\author{
Daniel M. Wall'1, C.V. Srikanth², Beth A. McCormick ${ }^{2}$ \\ 1 Institute of Infection, Immunity and Inflammation, College of Medical, Veterinary and Life Sciences, University of Glasgow, \\ G12 8QQ, United Kingdom. \\ 2 Department of Microbiology and Physiological Systems, University of Massachusetts Medical School, 55 Lake Avenue \\ North, Worcester, MA 01655, United States of America.
}

Correspondence to: Beth A. McCormick, email: Beth.McCormick@umassmed.edu

Keywords: Salmonella, cancer, therapy, tumor targeting, bacteria

Received: December 23, 2010, Accepted: Date 29, 2010, Published: January 3, 2011

Copyright: @ Wall et al. This is an open-access article distributed under the terms of the Creative Commons Attribution License, which permits unrestricted use, distribution, and reproduction in any medium, provided the original author and source are credited.

\section{ABSTRACT:}

\begin{abstract}
When one considers the organism Salmonella enterica serotype Typhimurium ( $S$. Typhimurium), one usually thinks of the Gram-negative enteric pathogen that causes the severe food borne illness, gastroentertitis. In this context, the idea of Salmonella being exploited as a cancer therapeutic seems pretty remote. However, there has been an escalating interest in the development of tumor-therapeutic bacteria for use in the treatment of a variety of cancers. This strategy takes advantage of the remarkable ability of certain bacteria to preferentially replicate and accumulate within tumors. In the case of $S$. Typhimurium, this organism infects and selectively grows within implanted tumors, achieving tumor/normal tissue ratios of approximately 1,000:1. Salmonella also has some attractive properties well suited for the design of a chemotherapeutic agent. In particular, this pathogen can easily be manipulated to carry foreign genes, and since this species is a facultative anaerobe, it is able to survival in both oxygenated and hypoxic conditions, implying this organism could colonize both small metastatic lesions as well as larger tumors. These observations are the impetus to a burgeoning field focused on the development of Salmonella as a clinically useful anti-cancer agent. We will discuss three cutting edge technologies employing Salmonella to target tumors.
\end{abstract}

\section{INTRODUCTION}

Bacteria have been investigated as therapeutic agents for tumors for over 150 years, when it was first observed by William B. Coley that a fraction of cancer patients who developed post-operative bacterial infections went into remission and were cured of their tumors [1]. Although the mechanisms underlying this observation were unclear, it was known even then that bacteria exhibit immunostimulatory properties. Moreover, it has been known for nearly 50 years that anaerobic bacteria can selectively grow in tumors, underscoring the fact that such microbes have the potential to overcome many of the delivery barriers that hinder conventional chemotherapeutics [2]. In particular, the conditions that permit anaerobic bacterial growth, such as impaired circulation, and extensive necrosis, are found in many tumors signifying that bacterial therapeutic conduits may serve as a unique portal to a wide variety of malignancies. Recent advances in molecular biology, as well as the complete sequencing of many bacterial genomes, have fueled a resurgence of interest in bacteria as drug delivery vehicles and tumoricidal agents. Here we will highlight recent advances exploiting the use of the food-borne pathogen Salmonella enterica serotype Typhimurium $(S$. Typhimurium), as an intriguing chemotherapeutic agent.

\section{THE BENEFITS OF BACTERIALCANCER THERAPY}

Current chemotherapeutics (and radiation) used in the treatment of cancer patients have considerable limitations, including toxicity, poor tumor targeting, and inadequate tissue penetration, which together often 
result in incomplete destruction of the tumors. Selected bacteria, however, can be manipulated to overcome many of the limitations that frequently hamper current cancer regiments by directly targeting cancer cells, killing these cells through innate bacterial toxicity, competition for nutrients or delivery of anti-cancer agents. Salmonella, Clostridium, Escherichia, Bifodobacterium, Caulobacter and Listeria species have all been tested for their potential use in cancer therapy with varying degrees of success $[3,4,5,6,7,8]$.

Bacterial toxins that are highly immunogenic have also been manipulated by linking them to tumor antigens in an attempt to elicit an immune response to tumors and sensitize the immune system to tumor presence $[9,10]$. Furthermore, bacteria such as S. Typhimurium have an innate advantage as a chemotherapeutic considering they are attracted to cancer cells by compounds released by necrotic or quiescent cells within the tumor, thereby they can be used to either infect cells or deliver compounds directly to the tumor site $[8,11,12,13]$. Interestingly, bacteria have also evolved to overcome several of the limitations of conventional therapy given that these organisms can penetrate deep into tumors and are unaffected by the immune evasion strategies deployed by tumors that can make cancer treatment so challenging (Figure 1).

\section{SALMONELLA TYPHIMURIUM AS A TREATMENT OPTION}

Clostridium and Salmonella species have historically been used most successfully as anti-cancer microbes $[1,2,14,15,16]$. These organisms have been used directly as therapeutics, as well as delivery vehicles for anti-

\section{Conventional Therapy}

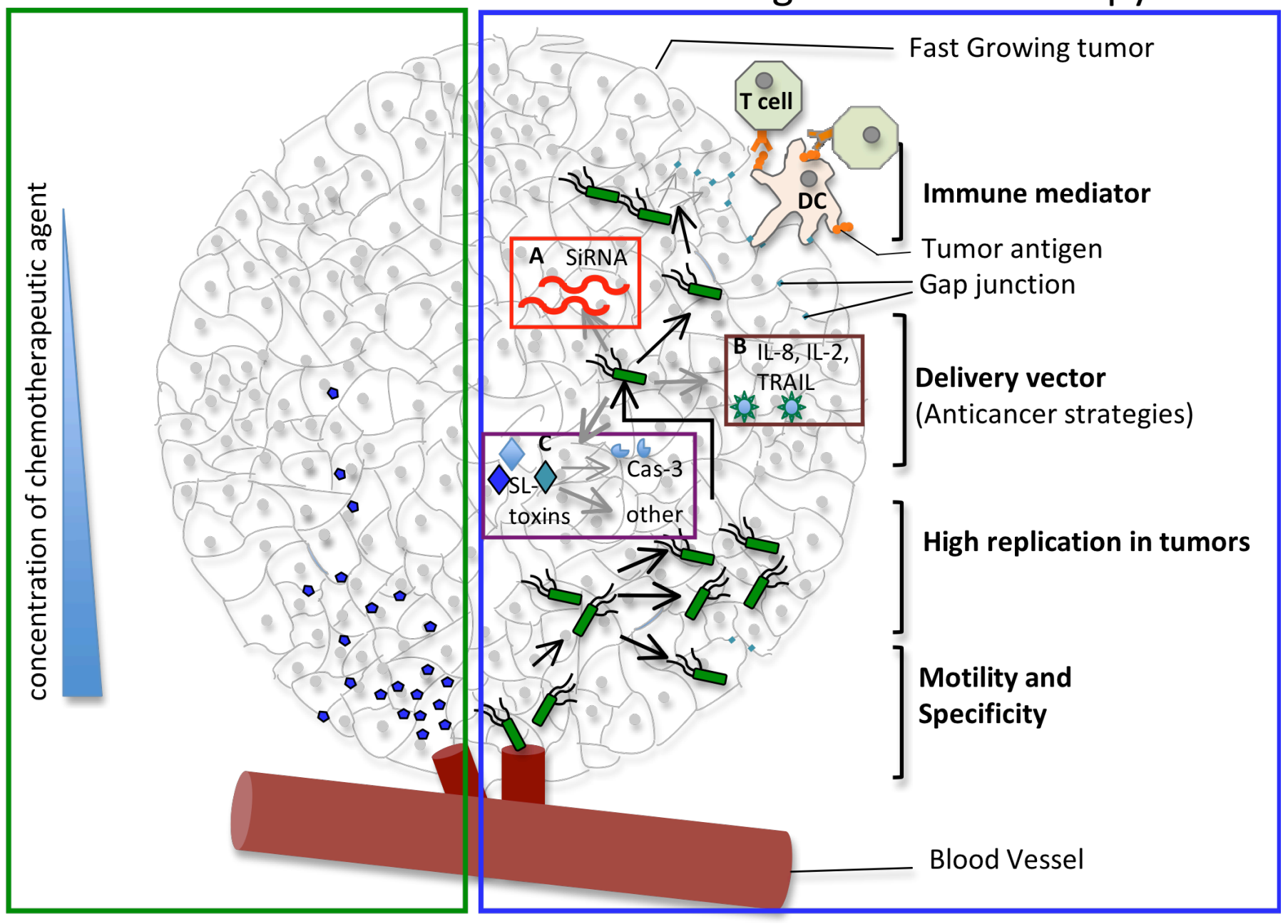

Figure 1: Schematic representing the advantages offered by Salmonella (SL) as a cancer therapeutic agent. Green box represents how the conventional chemotherapeutic agent (blue pentagon) is unable to penetrate deep into the fast growing tumor. Blue box represents the engineered-Salmonella therapy. Salmonella offers several advantages like (i) tumor-specificity, (ii)self-replicating potential, (iii) ability to be genetically engineered with either (a) gene silencing (red box), or (b) tumor sensitizing (brown box) or (c) bacterial toxin/effectors producing methodologies (purple box), leading to tumor regression by caspase-3 mediated and other mechanisms, (iv) ability to migrate to distal regions of the tumor and (v) most importantly to induce gap-junction in tumors leading to immune activation against the tumor. 
cancer therapeutics. However, recent advances in tumor targeting with attenuated $S$. Typhimurium have selected this pathogen as the bacterium of choice for cancer therapy development resulting in it being employed in human trials $[17,18,19]$. Moreover, unlike the strictly anaerobic Clostridium which must be delivered in spore form, $S$. Typhimurium is motile, easily genetically manipulated, and grows as a facultative anaerobe in the presence or absence of oxygen. These and other advantages (summarized in Table 1) allow $S$. Typhimurium to not only target tumors, but also deliver therapeutic compounds or immune modulators to the tumor site.

The anoxic environment often found in tumors makes the tumor site an attractive niche for $S$. Typhimurium growth. Through the use of their flagella, Salmonella migrate towards the tumor, attracted by the high concentrations of nutrients available within the tumor microenvironment $[20,21,22]$. The metabolism of $S$. Typhimurium has been exploited to attenuate the strains used in cancer therapy, manipulating the bacteria so that they grow only at tumor sites. Metabolic genes have been removed from $S$. Typhimurium, such as purI in the

\begin{tabular}{|c|c|c|}
\hline Feature & Underlying Reason & References \\
\hline Systemic administration & $\begin{array}{l}\text { VNP20009 can be delivered intravenously or by } \\
\text { direct injection into a tumor }\end{array}$ & {$[17,35,44]$} \\
\hline Tumor specificity & $\begin{array}{l}\text { Salmonella can accumulate at levels } 1,000 \text { fold } \\
\text { higher in tumors as opposed to normal tissues } \\
\text { reducing the risk of toxic side effects of proteins } \\
\text { or compounds delivered systemically. }\end{array}$ & {$[21,45,46]$} \\
\hline Replication competent & $\begin{array}{l}\text { Unlike other therapeutic agents Salmonella } \\
\text { replicates at the tumor site so that a low-dose } \\
\text { replicates to an effective dose within the target } \\
\text { tumor }\end{array}$ & {$[24,44,45,47]$} \\
\hline Broad tumor specificity & $\begin{array}{l}\text { Salmonella targets a broad range of solid tumors, } \\
\text { including melanoma, lung, colon, breast, renal, } \\
\text { hepatic, and prostate tumors }\end{array}$ & $\begin{array}{l}{[22,48,49,50,51,5} \\
2,53,54,55]\end{array}$ \\
\hline Delivery capacity & $\begin{array}{l}\text { Salmonella is metabolically active and can } \\
\text { continuously produce a protein of interest during } \\
\text { infection of the tumor }\end{array}$ & {$[10,37,56,57,58]$} \\
\hline $\begin{array}{l}\text { Anti-tumor Immune } \\
\text { activation }\end{array}$ & $\begin{array}{l}\text { Salmonella infection induces the upregulation of } \\
\text { Cx43 protein. This results in the formation of } \\
\text { functional Gap-junctions in tumors leading to } \\
\text { transfer of tumor antigenic peptides to the DCs } \\
\text { and eventually recruiting CD8 T cells }\end{array}$ & {$[32,34,59]$} \\
\hline Antibiotic sensitivity & $\begin{array}{l}\text { Salmonella can be easily removed following } \\
\text { treatment with antibiotics }\end{array}$ & \\
\hline Native cytotoxicity & $\begin{array}{l}\text { Ability of the bacteria to produce virulence factors } \\
\text { that leads to cytotoxicity and attract immune cells } \\
\text { to the tumors helps in further tumor regression }\end{array}$ & {$[50,60]$} \\
\hline Post delivery detection & $\begin{array}{l}\text { Engineered Salmonella expresses fluorescent } \\
\text { proteins that offers the ability to be externally } \\
\text { detected }\end{array}$ & {$[47,61,62,63]$} \\
\hline
\end{tabular}

Table 1: Advantages of Salmonella as an anti-tumor agent 
mutant strain VNP20009, rendering the mutant bacterium auxotrophic for certain compounds that are found in very high concentrations at tumor sites, in this case purines [23]. Such genetic engineering, forces migration of $S$. Typhimurium towards tumors in order to survive and results in the bacteria accumulating at the tumor site at over a 1,000 times higher levels than in normal tissue [24].

Migration towards the tumor site is based on the ability of $S$. Typhimurium to sense nutrients using a number of receptors that are located at the bacterial poles on the outer membrane of the bacteria. Two notable receptors have been characterized; the TAR receptor, which detects aspartate secreted by cancerous tissues and the TRG receptor, which aids in migration towards ribose found in necrotic tissues [21]. Further manipulation of this ability to chemotax towards tumors may lead to the development of bacteria that are directed toward specific regions within tumors. Towards this end, it was discovered that the aspartate receptor controls migration towards tumors, the serine receptor initiates penetration, and the ribose/galactose receptor directs Salmonella into necrotic regions [21]. Therefore knocking out a particular receptor may help direct Salmonella to particular region within the tumor. Other alterations, such as truncation of lipid A [23], reduces the immunogenicity of the bacteria, which in turn, reduces the risk of an adverse inflammatory reaction and possible toxic shock.

\section{EXPLOITING SALMONELLA TYPHIMURIUM TUMOR TARGETING}

$S$. Typhimurium, once at the tumor site, is thought to help destroy tumors through competition for nutrients and innate toxicity as a result of damage due to growth of the bacteria and production of toxins. Presently, $S$. Typhimurium is being used to target and destroy tumors in three specific ways: i) delivery of anti cancer compounds, ii) sensitizing the immune system to the presence of tumors, and iii) using bacterial toxins to directly activate caspase-3, a key enzyme of the apoptotic pathway (Figure 1).

\section{Using Salmonella to deliver anti cancer compounds:}

Bacteria have been recently described as "tiny programmable robot factories" for use in cancer therapy [25]. Indeed, there are numerous compounds that can be delivered via bacteria to a tumor site including cytotoxic agents, green fluorescent protein for targeting and visualization of tumors, DNA for gene therapy, and small interfering RNAs (siRNA) to target expression of key proteins within tumors [11,22,26,27,28,29,30,31]. While these techniques have had varying levels of success in animal models, it is inferred that these practices when used in combination with the native toxicity of Salmonella may offer a fascinating alternative to traditional gene therapy approach.

It is envisaged that specific anti-cancer molecules delivered by $S$. Typhimurium can be used to target the outer regions of the tumor with the bacteria invading deep within the tumor, penetrating regions of the tumor architecture that conventional therapies cannot reach $[12,32]$. One of the key challenges with conventional chemotherapy is delivery of potentially toxic agents to the appropriate areas of the tumor while preventing damage to healthy tissue. Temporal control over bacterial delivery of therapeutic agents is a key consideration as delivery of these compounds during transit to the tumor site will distribute products systemically and increase toxicity in healthy tissues. Inducible gene promoters offer a solution that is presently employed. Detection of small molecules by the bacteria, or irradiation at the point where expression is required, have both been used successfully in vivo along with the use of pro-drugs introduced at the tumor site for conversion into an anticancer agent by the bacteria upon contact $[13,32,33]$. $r e c A$, the radiation inducible promoter, was linked to tumor necrosis factor (TNF)-related apoptosis inducing ligand (TRAIL) to control its expression by Salmonella during infection of tumors [32]. S. Typhimurium at the tumor site was then induced to express TRAIL by doses of radiation, which simultaneously treated the tumor. $S$. Typhimurium promoters specifically induced by hypoxia have been identified and may be of use in the future, with bacterial expression of a therapeutic compound activated once the bacteria reach the tumor [33].

A second approach for controlling therapeutic delivery is the construction of bacteria that produce enzymes converting harmless pro-drugs into active agents inside the tumor. Toward this goal Salmonella has been engineered to express cytosine deaminase (CDase) that cleaves the pro-drug 5-fluorocytosine to the active chemotherapeutic 5-fluorouricil $[13,18]$.

\section{Using Salmonella to sensitize the immune system to the presence of tumors:}

The ignorance of the immune system to the presence of tumors within the body is a significant consideration in attempting to treat cancer. While numerous methods have been attempted to alert the immune system to the presence of tumors, recent work has shed new light on the role that Salmonella, in particular, plays in this process. $S$. Typhimurium infection of cancer cells was shown to upregulate the cellular protein connexin43, resulting in gap junction formation not only between tumor cells but also between cancer cells and antigen presenting cells (APCs) [34]. This allows APCs access to pre-processed tumor antigens, which they can then present to T-cells, 
sensitizing the immune system to the presence of tumors and activating an anti-tumor response. This ability to sensitize the immune system to the presence of tumors may explain some of the success Salmonella has in combating tumors. Alternative methods of sensitizing the immune system through Salmonella targeting of tumors have also been used.

Other approaches employ $S$. Typhimurium to deliver cytokines to the tumor site in an attempt to activate immune cells or elicit an immune response against the tumor [8,10,35,36,37,38,39]. Antigens have also been linked to bacterial toxins that are highly immunogenic to sensitize the immune system against cancer cell antigens $[10,40]$. Again, this approach harnesses the ability of $S$. Typhimurium to deliver immune sensitizing compounds at the tumor site to alert circulating immune cells, while at the same time the bacteria target the more difficult to reach anoxic regions of the tumor.

\section{Using bacterial toxins to directly activate caspase-3:}

It is becoming increasingly evident that the ability to control or inhibit apoptosis affords a distinct advantage to certain bacterial pathogens, as it allows the organism to replicate within the infected cell, increasing the chance of a successful infection. Although a number of bacteria specifically inhibit apoptosis, our recent evidence indicates that $S$. Typhimurium may activate specific apoptotic enzymes [41]. We found that activation of caspase- 3 by a single effector protein of $S$. Typhimurium increases the infectivity of this pathogen, as caspase- 3 directed the processing of $S$. Typhimurium secreted effectors into their functional subunits upon their delivery into the host cell [42]. Such an unprecedented means of promoting infection indicates that the interaction of bacteria with apoptotic pathways may be more intimate than previously recognized, and in fact, may be quite common amongst pathogens.

This observation raises a key question with regards to $S$. Typhimurium therapy for cancer - can we use bacteria to exploit apoptotic pathways, and in particular activation of caspase-3, opening a new front in the fight against cancer? Direct activation of caspase- 3 in the treatment of cancer through using procaspase- 3 activating compounds has been attempted previously using pan activating caspase-1 (PAC-1) [43]. Thus, employing an efficient bacterial vector to directly deliver a native bacterial effector for caspase- 3 activation offers a different approach to bacterial therapy. Rather than deliver large quantities of non native proteins, it may be possible to channel the built-in toxicity of $S$. Typhimurium to destroy tumors. $S$. Typhimurium also harbors several promoters that are induced under hypoxic conditions, and using these promoters to control expression of specific effectors may offer novel opportunities to utilize the innate bacterial toxicity. In particular, $S$. Typhimurium may perhaps be engineered to up-regulate caspase-3 through effector expression while at the same time introducing potent anticancer drugs that can no longer be successfully expelled by the tumor.

\section{FUTURE DIRECTIONS FOR SALMONELLA CANCER THERAPY}

In sum, bacterial cancer therapy has made great strides in past decade, and is now considered a tangible option for future cancer therapy. The potential for bacterial therapy seems endless but some fundamental issues need to be reconciled before this kind of therapy moves into a clinic setting. Insufficient colonization of tumors appears to be the major obstacle identified in clinical trials, a problem that was not evident in animal models. Overcoming this challenge is one of the priorities in developing bacteria as cancer therapy agents. But the ease of genetic manipulation in $S$. Typhimurium may prove to be the key in surmounting this hurdle. Toxicity of $S$. Typhimurium is also problematic, with the bacteria too attenuated to destroy tumors once at the tumor site due to toxin removal, or poor expression of anti-cancer compounds, or the risks of toxicity are too great for injection of $S$. Typhimurium into severely immunocompromised patients. Overcoming these limitations, particularly with respect to using bacterial proteins in therapy, are key to moving this aspect of bacterial cancer therapy forward.

\section{ACKNOWLEDGEMENTS:}

DMW is funded by Tenovus Scotland. B.A.M. is funded by National Institutes of Health (DK56754 and DK33506), and the Crohn's and Colitis Foundation of America.

\section{REFERENCES:}

1. McCarthy EF. The toxins of William B. Coley and the treatment of bone and soft-tissue sarcomas. Iowa Orthop J 2006; 26: 154-158.

2. Carey RW, Holland HF, Whang HY, Neter E, Bryant B. Clostridial oncolysis in man. Eur J Cancer 1967; 3: 37-46.

3. Leschner S, Weiss S. Salmonella-allies in the fight against cancer. J Mol Med 2010; 88: 763-773.

4. Mengesha A, Wei JZ, Zhou SF, Wei MQ. Clostridial spores to treat solid tumours - potential for a new therapeutic modality. Curr Gene Ther 2010; 10: 15-26.

5. Stritzker J, Weibel S, Hill PJ, Oelschlaeger TA, Goebel W, Szalay AA. Tumor-specific colonization, tissue distribution, and gene induction by probiotic Escherichia coli Nissle 1917 in live mice. Int J Med Microbiol 2007; 297: 151-162. 
6. Hu B, Kou L, Li C, Zhu LP, Fan YR, Wu ZW, Wang JJ, $\mathrm{Xu}$ GX. Bifidobacterium longum as a delivery system of TRAIL and endostatin cooperates with chemotherapeutic drugs to inhibit hypoxic tumor growth. Cancer Gene Ther 2009; 16: 655-663.

7. Bhatnagar PK, Awasthi A, Nomellini JF, Smit J, Suresh MR. Anti-tumor effects of the bacterium Caulobacter crescentus in murine tumor models. Cancer Biol Ther 2006; 5: 485-491.

8. Paterson Y, Guirnalda PD, Wood LM. Listeria and Salmonella bacterial vectors of tumor-associated antigens for cancer immunotherapy. Semin Immunol 2010; 22: 183 189.

9. Wang YJ, Hou Y, Huang H, Liu GR, White AP, Liu SL. Two oral HBx vaccines delivered by live attenuated Salmonella: both eliciting effective anti-tumor immunity. Cancer Lett 2008; 263: 67-76.

10. Fensterle J, Bergmann B, Yone CL, Hotz C, Meyer SR, Spreng S, Goebel W, Rapp UR, Gentschev I. Cancer immunotherapy based on recombinant Salmonella enterica serovar Typhimurium aroA strains secreting prostatespecific antigen and cholera toxin subunit B. Cancer Gene Ther 2008; 15: 85-93.

11. Zhu X, Cai J, Huang J, Jiang X, Ren D. The treatment and prevention of mouse melanoma with an oral DNA vaccine carried by attenuated Salmonella typhimurium. J Immunother 2010; 33: 453-460.

12. Moreno M, Kramer MG, Yim L, Chabalgoity JA. Salmonella as live trojan horse for vaccine development and cancer gene therapy. Curr Gene Ther 2010; 10: 56-76.

13. King I, Itterson M, Bermudes D. Tumor-targeted Salmonella typhimurium overexpressing cytosine deaminase: a novel, tumor-selective therapy. Methods Mol Biol 2009; 542: 649-659.

14. Dang LH, Bettegowda C, Huso DL, Kinzler KW, Vogelstein B. Combination bacteriolytic therapy for the treatment of experimental tumors. Proc Natl Acad Sci U S A 2001; 98: 15155-15160.

15. Wei MQ, Ellem KA, Dunn P, West MJ, Bai CX, Vogelstein B. Facultative or obligate anaerobic bacteria have the potential for multimodality therapy of solid tumours. Eur J Cancer 2007; 43: 490-496.

16. Cheong I, Huang X, Bettegowda C, Diaz LA, Jr., Kinzler KW, Zhou S, Vogelstein B. A bacterial protein enhances the release and efficacy of liposomal cancer drugs. Science 2006; 314: 1308-1311.

17. Toso JF, Gill VJ, Hwu P, Marincola FM, Restifo NP, Schwartzentruber DJ, Sherry RM, Topalian SL, Yang JC, Stock F, Freezer LJ, Morton, KE, Seipp C, Haworth L, Mavroukakis S, White D, et al. Phase I study of the intravenous administration of attenuated Salmonella typhimurium to patients with metastatic melanoma. J Clin Oncol 2002; 20: 142-152.

18. Nemunaitis J, Cunningham C, Senzer N, Kuhn J, Cramm
J, Litz C, Cavagnolo R, Cahill A, Clairmont C, Sznol M. Pilot trial of genetically modified, attenuated Salmonella expressing the $E$. coli cytosine deaminase gene in refractory cancer patients. Cancer Gene Ther 2003; 10: 737-744.

19. Heimann DM, Rosenberg SA. Continuous intravenous administration of live genetically modified Salmonella typhimurium in patients with metastatic melanoma. J Immunother 2003; 26: 179-180.

20. Hoffman RM. Tumor-targeting amino acid auxotrophic Salmonella typhimurium. Amino Acids 2009; 37: 509-521.

21. Kasinskas RW, Forbes NS. Salmonella typhimurium lacking ribose chemoreceptors localize in tumor quiescence and induce apoptosis. Cancer Res 2007; 67: 3201-3209.

22. Zhao M, Yang M, Ma H, Li X, Tan X, Li S, Yang Z, Hoffman RM. Targeted therapy with a Salmonella typhimurium leucine-arginine auxotroph cures orthotopic human breast tumors in nude mice. Cancer Res 2006; 66: 7647-7652.

23. Low KB, Ittensohn M, Luo X, Zheng LM, King I, Pawelek JM, Bermudes D. Construction of VNP20009: a novel, genetically stable antibiotic-sensitive strain of tumortargeting Salmonella for parenteral administration in humans. Methods Mol Med 2004; 90: 47-60.

24. Clairmont C, Lee KC, Pike J, Ittensohn M, Low KB, Pawelek J, Bermudes D, Brecher SM, Margitich D, Turnier J, Li Z, Luo X, King I, Zheng LM. Biodistribution and genetic stability of the novel antitumor agent VNP20009, a genetically modified strain of Salmonella typhimurium. J Infect Dis 2000; 181: 1996-2002.

25. Forbes NS. Engineering the perfect (bacterial) cancer therapy. Nat Rev Cancer 2010; 10: 785-794.

26. Yu YA, Shabahang S, Timiryasova TM, Zhang Q, Beltz R, Gentschev I, Goebel W, Szalay AA. Visualization of tumors and metastases in live animals with bacteria and vaccinia virus encoding light-emitting proteins. Nat Biotechnol 2004; 22: 313-320.

27. Ruan Z, Yang Z, Wang Y, Wang H, Chen Y, Shang X, Yang $\mathrm{C}$, Guo S, Han J, Liang $\mathrm{H}$, Wu Y. DNA vaccine against tumor endothelial marker 8 inhibits tumor angiogenesis and growth. J Immunother 2009; 32: 486-491.

28. Xu DQ, Zhang L, Kopecko DJ, Gao L, Shao Y, Guo B, Zhao L. Bacterial delivery of siRNAs: a new approach to solid tumor therapy. Methods Mol Biol 2009; 487: 161187.

29. Basu D, Herlyn M. Salmonella typhimurium as a novel RNA interference vector for cancer gene therapy. Cancer Biol Ther 2008; 7: 151-152.

30. Jiang Z, Zhao P, Zhou Z, Liu J, Qin L, Wang H. Using attenuated Salmonella typhi as tumor targeting vector for MDR1 siRNA delivery. Cancer Biol Ther 2007; 6: 555560.

31. MacDiarmid JA, Amaro-Mugridge NB, Madrid-Weiss J, Sedliarou I, Wetzel S, Kochar K, Brahmbhatt VN, Phillips L, Pattison ST, Petti C, Stillman B, Graham RM, 
Brahmbhatt H. Sequential treatment of drug-resistant tumors with targeted minicells containing siRNA or a cytotoxic drug. Nat Biotechnol 2009; 27: 643-651.

32. Ganai S, Arenas RB, Forbes NS. Tumour targeted delivery of TRAIL using Salmonella typhimurium enhances breast cancer survival in mice. Br J Cancer 2009; 101: 1683-1691.

33. Mengesha A, Dubois L, Lambin P, Landuyt W, Chiu RK, Wouters BG, Theys J. Development of a flexible and potent hypoxia-inducible promoter for tumor-targeted gene expression in attenuated Salmonella. Cancer Biol Ther 2006; 5: 1120-1128.

34. Saccheri F, Pozzi C, Avogadri F, Barozzi S, Faretta M, Fusi $\mathrm{P}$, Rescigno M. Bacteria-induced gap junctions in tumors favor antigen cross-presentation and antitumor immunity. Sci Transl Med 2010; 2: 44ra57.

35. al-Ramadi BK, Fernandez-Cabezudo MJ, El-Hasasna H, Al-Salam S, Bashir G, Chouaib S. Potent anti-tumor activity of systemically-administered IL2-expressing Salmonella correlates with decreased angiogenesis and enhanced tumor apoptosis. Clin Immunol 2009; 130: 89-97.

36. Saltzman DA, Heise CP, Hasz DE, Zebede M, Kelly SM, Curtiss R 3rd, Leonard AS, Anderson PM. Attenuated Salmonella typhimurium containing interleukin-2 decreases MC-38 hepatic metastases: a novel anti-tumor agent. Cancer Biother Radiopharm 1996; 11: 145-153.

37. Loeffler M, Le'Negrate G, Krajewska M, Reed JC. IL-18producing Salmonella inhibit tumor growth. Cancer Gene Ther 2008; 15: 787-794.

38. Loeffler M, Le'Negrate G, Krajewska M, Reed JC. Attenuated Salmonella engineered to produce human cytokine LIGHT inhibit tumor growth. Proc Natl Acad Sci U S A 2007; 104: 12879-12883.

39. Nishikawa H, Sato E, Briones G, Chen LM, Matsuo M, Nagata Y, Ritter G, Jäger E, Nomura H, Kondo S, Tawara I, Kato T, Shiku H, Old LJ, Galán JE, Gnjatic S. In vivo antigen delivery by a Salmonella typhimurium type III secretion system for therapeutic cancer vaccines. J Clin Invest 2006; 116: 1946-1954.

40. Zhu X, Zhou P, Cai J, Yang G, Liang S, Ren D. Tumor antigen delivered by Salmonella III secretion protein fused with heat shock protein 70 induces protection and eradication against murine melanoma. Cancer Sci 2010; 101: 2621-2628.

41. Srikanth CV, Wall DM, Maldonado-Contreras A, Shi HN, Zhou D, Demma Z, Mumy KL, McCormick BA. Salmonella pathogenesis and processing of secreted effectors by caspase-3. Science 2010; 330: 390-393.

42. Wall DM, Nadeau WJ, Pazos MA, Shi HN, Galyov EE, McCormick BA. Identification of the Salmonella enterica serotype typhimurium SipA domain responsible for inducing neutrophil recruitment across the intestinal epithelium. Cell Microbiol 2007; 9: 2299-2313.

43. Peterson QP, Hsu DC, Goode DR, Novotny CJ, Totten RK, Hergenrother PJ. Procaspase-3 activation as an anti-cancer strategy: structure-activity relationship of procaspaseactivating compound 1 (PAC-1) and its cellular colocalization with caspase-3. J Med Chem 2009; 52: 57215731.

44. Forbes NS, Munn LL, Fukumura D, Jain RK. Sparse initial entrapment of systemically injected Salmonella typhimurium leads to heterogeneous accumulation within tumors. Cancer Res 2003; 63: 5188-5193.

45. Kasinskas RW, Forbes NS. Salmonella typhimurium specifically chemotax and proliferate in heterogeneous tumor tissue in vitro. Biotechnol Bioeng 2006; 94: 710-721.

46. Pawelek JM, Low KB, Bermudes D. Tumor-targeted Salmonella as a novel anticancer vector. Cancer Res 1997; 57: 4537-4544.

47. Zhao M, Yang M, Li XM, Jiang P, Baranov E, Li S, Xu M, Penman S, Hoffman RM. Tumor-targeting bacterial therapy with amino acid auxotrophs of GFP-expressing Salmonella typhimurium. Proc Natl Acad Sci U S A 2005; 102: 755-760.

48. Maletzki C, Linnebacher M, Kreikemeyer B, Emmrich J. Pancreatic cancer regression by intratumoural injection of live Streptococcus pyogenes in a syngeneic mouse model. Gut 2008; 57: 483-491.

49. Nagakura C, Hayashi K, Zhao M, Yamauchi K, Yamamoto N, Tsuchiya H, Tomita K, Bouvet M, Hoffman RM. Efficacy of a genetically-modified Salmonella typhimurium in an orthotopic human pancreatic cancer in nude mice. Anticancer Res 2009; 29: 1873-1878.

50. Lee CH, Wu CL, Shiau AL. Salmonella choleraesuis as an anticancer agent in a syngeneic model of orthotopic hepatocellular carcinoma. Int J Cancer 2008; 122: 930-935.

51. Barnett SJ, Soto LJ, 3rd, Sorenson BS, Nelson BW, Leonard AS, Saltzman DA. Attenuated Salmonella typhimurium invades and decreases tumor burden in neuroblastoma. J Pediatr Surg 2005; 40: 993-997; discussion 997-998.

52. Zhang L, Gao L, Zhao L, Guo B, Ji K, Tian Y, Wang J, Yu H, Hu J, KalvakolanuDV, Kopecko DJ, Zhao X, Xu DQ. Intratumoral delivery and suppression of prostate tumor growth by attenuated Salmonella enterica serovar typhimurium carrying plasmid-based small interfering RNAs. Cancer Res 2007; 67: 5859-5864.

53. Kimura H, Zhang L, Zhao M, Hayashi K, Tsuchiya H, Tomita K, Bouvet M, Wessels J, Hoffman RM. Targeted therapy of spinal cord glioma with a genetically modified Salmonella typhimurium. Cell Prolif 2010; 43: 41-48.

54. Jazowiecka-Rakus J, Szala S. Antitumour activity of Salmonella typhimurium VNP20047 in B16(F10) murine melanoma model. Acta Biochim Pol 2004; 51: 851-856.

55. Friedlos F, Lehouritis P, Ogilvie L, Hedley D, Davies L, Bermudes D, King I, Martin J, Marais R, Springer CJ. Attenuated Salmonella targets prodrug activating enzyme carboxypeptidase G2 to mouse melanoma and human breast and colon carcinomas for effective suicide gene therapy. Clin Cancer Res 2008; 14: 4259-4266. 
56. Loeffler M, Le'Negrate G, Krajewska M, Reed JC. Salmonella typhimurium engineered to produce CCL21 inhibit tumor growth. Cancer Immunol Immunother 2009; 58: 769-775.

57. Pertl U, Wodrich H, Ruehlmann JM, Gillies SD, Lode HN, Reisfeld RA. Immunotherapy with a posttranscriptionally modified DNA vaccine induces complete protection against metastatic neuroblastoma. Blood 2003; 101: 649-654.

58. Niethammer AG, Xiang R, Ruehlmann JM, Lode HN, Dolman CS, Gillies SD, Reisfeld RA. Targeted interleukin 2 therapy enhances protective immunity induced by an autologous oral DNA vaccine against murine melanoma. Cancer Res 2001; 61: 6178-6184.

59. Loeffler M, Le’Negrate G, Krajewska M, Reed JC. Inhibition of tumor growth using Salmonella expressing Fas ligand. J Natl Cancer Inst 2008; 100: 1113-1116.

60. Sznol M, Lin SL, Bermudes D, Zheng LM, King I. Use of preferentially replicating bacteria for the treatment of cancer. J Clin Invest 2000, 105: 1027-1030.

61. Nguyen VH, Kim HS, Ha JM, Hong Y, Choy HE, Min JJ. engineered Salmonella typhimurium as an imageable therapeutic probe for cancer. Cancer Res 2010; 70: 18-23.

62. Hoffman RM, Zhao M. Whole-body imaging of bacterial infection and antibiotic response. Nat Protoc 2006; 1: 29882994.

63. Tjuvajev J, Blasberg R, Luo X, Zheng LM, King I, Bermudes D. Salmonella-based tumor-targeted cancer therapy: tumor amplified protein expression therapy (TAPET) for diagnostic imaging. J Control Release 2001; 74: 313-315. 